\title{
Review
}

\section{Experience of rehabilitation following spinal cord injury: a meta-synthesis of qualitative findings}

\author{
K Whalley Hammell*,1 \\ ${ }^{1}$ Research, Oxbow, Saskatchewan, Canada
}

\begin{abstract}
Study design: Meta-synthesis of qualitative research.
Objectives: To identify, compare and synthesize published qualitative evidence concerning the experience of rehabilitation following spinal cord injury (SCI).

Methods: Published articles were identified from the Medline, CINAHL and Sociological abstracts databases, a hand search through selected journals published since 1990, and from reference lists. These were assessed for their relevance to the focus of interest and appraised for rigour. The key themes that emerged from the data were summarized, compared and synthesized.
\end{abstract}

Results: The search located 64 papers and four books, of which eight papers (describing seven studies) met the review criteria for relevance and rigour. Thematic comparison and synthesis resulted in the identification of seven concepts that encapsulate the important dimensions of rehabilitation from participants' perspectives: (1) the importance of specific staff qualities; (2) the need for a vision of future life possibilities; (3) the importance of peers; (4) the relevance of programme content; (5) the institutional context of rehabilitation; (6) the importance of reconnecting the past to the future; (7) the importance of meeting the needs of the real world. Conclusions: If rehabilitation services are to be evidence-based, relevant and effective in meeting the needs of people with SCI they must be informed by the perspectives of people with SCI. The findings of this review suggest that the most important dimension of rehabilitation for people with SCI is the calibre and vision of the rehabilitation staff.

Sponsorship: N/A.

Spinal Cord (2007) 45, 260-274. doi:10.1038/sj.sc.3102034; published online 20 February 2007

Keywords: spinal cord injury; rehabilitation; qualitative research; meta-synthesis

\section{Introduction}

Legislation in several countries (eg Australia, Canada and the UK) requires service providers to ensure that health-care clients have direct input into the planning, development and evaluation of health-care services. ${ }^{1-5}$ This obliges rehabilitation professionals to seek clients' perspectives through research and to incorporate these perspectives into the planning and delivery of rehabilitation services. Therefore, evaluation of spinal cord injury (SCI) rehabilitation services should be undertaken from the perspectives of current and former users of those services. However, Carpenter ${ }^{6}$ (page no. 626) noted that there is a "dearth of studies ascertaining how persons with spinal cord injury perceive the rehabilitation instruction they received' and suggested that clinicians have therefore been able 'to deceive themselves that the

*Correspondence: KW Hammell, Researcher, Box 515, Oxbow, Saskatchewan, Canada S0C 2B0 traditional rehabilitation program constitutes the most effective and optimal method of service delivery'.

In the absence of a cure, rehabilitation is perceived by rehabilitation professionals to be of fundamental importance to people with SCI and yet few researchers have explored the experience of rehabilitation from the perspectives of current and former clients. ${ }^{7}$ In the $1980 \mathrm{~s}$, a film-maker who investigated the experience of rehabilitation following SCI in the USA reported: 'One thing common to everyone's story was that early on they'd been told more about what they couldn't do than what they could do:... you'll never walk, or go to school or graduate or get married or hold a job. You can't fly a plane, you can't make music, you can't have children. You can't be a doctor or get elected to public office. Get real. ${ }^{8}$ This report precisely matches that of a Canadian researcher, who documented the following impression of the 'message' that had been delivered by health-care professionals to people with high SCI during 
the 1970 s, 1980 s and 1990s: 'you will be dead within two years, you will never leave the hospital, you will never have a home, a job, a family and you will never travel: don't even think about it'. reports, their striking similarity, and their resonance with the observations of other rehabilitation clients ${ }^{10,11}$ has serious implications and merits conscientious scrutiny of the experience of rehabilitation following SCI.

\section{Literature review}

Few published studies have explored the experience of rehabilitation from patients' perspectives, ${ }^{11,12}$ although in the $1980 \mathrm{~s}$, two books explored the experience of SCI (including rehabilitation) among $\operatorname{men}^{13}$ and women ${ }^{10}$ in the UK. Oliver et $a l^{13}$ reported that men with SCI appreciated physiotherapy's approach to 'making the most' of their residual function. However, some felt that the rehabilitation process was akin to a 'conveyor belt', that there was little opportunity to participate in decision-making and that it was standard procedure to do certain things (page no. 79). There was a perceived discrepancy between physiotherapists' priorities and patients' own, with patients expressing a desire to have more of a partnership with their therapists. The highest praise came from a man who claimed to have been 'a difficult patient' because 'I knew what I wanted to do' and who perceived that his therapist 'did it absolutely right - she and I worked together to solve my problems' (page no. 80). Perceptions of the occupational therapy service were almost universally negative and it was concluded that 'greater choice and responsiveness to individual preferences would go some way to improving the adequacy of the occupational therapy service' (page no. 80).

Morris ${ }^{10}$ reported that women with SCI were cynical about the overwhelming emphasis in SCI units on physical achievement, sport and competition, experiencing this as oppressive and inappropriate. They believed that no thought was given to their needs as individuals and that the 'stupid' rules and rigid procedures of the rehabilitation centres reduced them to 'third class citizens' (page no. 30). Notably, complaints about poor communication, lack of attention to emotional needs and to their needs as women were as common among women injured in the $1980 \mathrm{~s}$ as they were among women injured in the $1950 \mathrm{~s}, 1960 \mathrm{~s}$ and $1970 \mathrm{~s}$. The women also reported that because staff held pessimistic views of their abilities they held out no useful vision for the women's future lives.

Rehabilitation's pervasive ideology of physical independence and concomitant preoccupation with reinforcing social norms of masculine physicality, outlined in the UK study ${ }^{10}$ were replicated in Seymour's ${ }^{14}$ book about SCI in Australia. This underlying ideology was perceived to have justified a form of 'functional élitism' that focused therapists' attention predominantly on those people with low levels of paraplegia who could most closely approximate the norms of the able-bodied world, while neglecting the needs of women and older people with SCI and those with higher levels of injury. The overwhelming emphasis on physicality was perceived to have precluded exploration of diverse avenues of potential and had fostered a narrow view of what sort of lives might be possible following SCI. ${ }^{14}$

A substantial body of quantitative research has assessed SCI rehabilitation outcomes using pre-determined criteria deemed important by researchers: notably employment status, 'adjustment' and self-care skills. Little research has attempted a more explorative, qualitative appraisal of the rehabilitation process and its relevance to the self-defined needs of patients. In the absence of a significant body of research exploring people with SCIs' perspectives on the relevance and usefulness of their rehabilitation experiences health-care professionals have no way of knowing whether they are meeting their patients' needs or facilitating their transition to community living. ${ }^{7}$ However, meta-synthesis constitutes a useful tool to maximize the knowledge currently available in existing experiential studies.

\section{Meta-synthesis}

Although incorporated only recently into the repertoire of rehabilitation researchers, qualitative methods are acknowledged to be important tools for illuminating the experiences, perspectives and contexts of people's lives. ${ }^{15,16}$ In an effort to overcome the inherent difficulty with generalizing qualitative findings (because of small sample sizes and non-representative samples) $)^{17-19}$ some health-care researchers have begun the work of combining the results of several qualitative studies on a specific issue to attain a greater depth of understanding than is possible from a single study. ${ }^{17,20,21}$ This is a metasynthesis: the examination, critical comparison and synthesis of a collection of published qualitative studies concerning a common topic. ${ }^{22}$ The process of metasynthesis entails identifying similarities and dissimilarities between the findings of existing studies. ${ }^{23}$

A qualitative meta-synthesis was deemed to be an appropriate means through which to explore peoples' perspectives of the experience of rehabilitation following SCI and with which to compile relevant and useful evidence to inform future rehabilitation practices.

Focus of review The purpose of this meta-synthesis was to determine what the published qualitative research literature contributes to understanding the patients' experience of in-patient rehabilitation following SCI.

\section{Methods}

The process of meta-synthesis comprised five phases (from Hammell ${ }^{24}$ ): Identification of the focus of review, identification of published papers and determination of their relevance, appraisal of the papers for research rigour and quality, identification and summary of themes from each paper that could be verified against 
the primary data (participants' perspectives), comparison of key themes between the papers such that the findings are linked across studies and synthesized into concepts. ${ }^{17,18,20,23,25,26}$

\section{Identifying published papers and determining their relevance}

Published papers were identified from the Medline, CINAHL and Sociological Abstracts databases, crossindexing two basic text phrases: 'SCI' and 'qualitative'. This was augmented by a hand search through relevant journals published since $1990^{24}$ and by papers identified through reference lists. Papers were neither selected nor rejected on the basis of the specific qualitative methods employed. The relevance of each paper was determined by whether it contained data pertaining to the experience of in-patient rehabilitation after SCI.

Appraising the papers for research rigour and quality As part of the process of the meta-synthesis, the quality of relevant studies was evaluated using predetermined criteria. $^{27,28}$ For the purposes of this review the following criteria were employed to gauge the quality of the studies identified in the search process. These criteria were based upon the work of scholars from the qualitative tradition ${ }^{19,27,29,30}$ and to the Critical Appraisal Skills Programme ${ }^{20}$ (see also Hammell ${ }^{24}$ ).

1. Presence of a clear statement of the purpose and relevance of the study (including literature review); ${ }^{19,31,32}$

2. The appropriateness of the methodology and methods; ${ }^{19,31,33}$

3. Appropriate methods of sampling and recruitment of participants; ${ }^{19,30,31}$

4. Transferability (information concerning the representativeness of the informants); ${ }^{19,34,35}$

5. Data quality: appropriate data collection process, methods and data documentation; $30,34,36$

6. Participants' perspectives, and evidence that participants' perspectives have been accorded primacy: the 'primary marker' of quality in qualitative research; ${ }^{27,36,37}$

7. Plausibility (audit trail): whether researchers' interpretations and analyses can be seen to have arisen from the data and whether they fit the data from which they are derived; ${ }^{19,30,31,35}$

8. Conclusions consistent with, and justified by the data. $^{31}$

The most important aspect of quality for papers to be included in a meta-synthesis is clear evidence that the themes reported by the original researchers were rooted in the data; ${ }^{17,20,26,27}$ thus papers were only included if there were adequate participants' perspectives to demonstrate the plausibility of the researchers' interpretations.

\section{Summarizing themes}

The perspectives of the various study participants were summarized and listed, using condensing labels. Themes that had been identified by the researchers were also noted, cross-checking these against their cited data to ensure both the plausibility of their interpretations and the consistency with which terminology was employed by the different researchers.

\section{Comparison of themes and conceptual synthesis}

Once the data in each paper had been summarized by labels these were charted under unifying headings. In an inductive and deductive process, relationships were identified and concepts were developed that synthesized the findings of all the papers included in the review.

\section{Results}

\section{Identifying published papers and determining their} relevance

The search identified 64 papers and four books (see reference Hammell ${ }^{24}$ ), of which three books and 15 papers had potential relevance to the review question. Seven papers of potential relevance were omitted from the review because they did not explore the experience of rehabilitation from patients' perspectives (the focus of this review) but specific, researcher-prioritized issues of goal setting, ${ }^{38}$ clinical reasoning, ${ }^{39}$ the role of the family, ${ }^{40}$ adaptation to wheelchair use, ${ }^{41}$ perceived rehabilitation needs ${ }^{42}$ and the experience of hope. ${ }^{43,44}$ Only two papers had sought explicitly to explore patients' perspectives of the experience of rehabilitation following SCI per se. Six further papers contained a significant quantity of data having clear relevance to the focus of interest and these eight papers were accordingly appraised for rigour.

\section{Result of appraising the papers for rigour and quality} The three books ${ }^{10,13,14}$ included insufficient information for appraisal of methodological rigour. All eight papers satisfied the criteria for rigour and quality established in the review guidelines. The demographic data of these studies are presented together in Table 1. Two papers report on different dimensions of the same study, thus the eight papers describe seven studies involving a total of 123 participants.

\section{Summary of themes that emerged from the data} Although only two of the papers ${ }^{45,46}$ had explicitly sought to explore the experience of rehabilitation following SCI, it perhaps indicates the importance of this experience for people with SCI, that perspectives on the rehabilitation processes emerged even in studies designed to probe other issues. Despite significant disparities in the nature of the questions posed to the various study participants the same issues arose repeatedly, with participants often using the same 


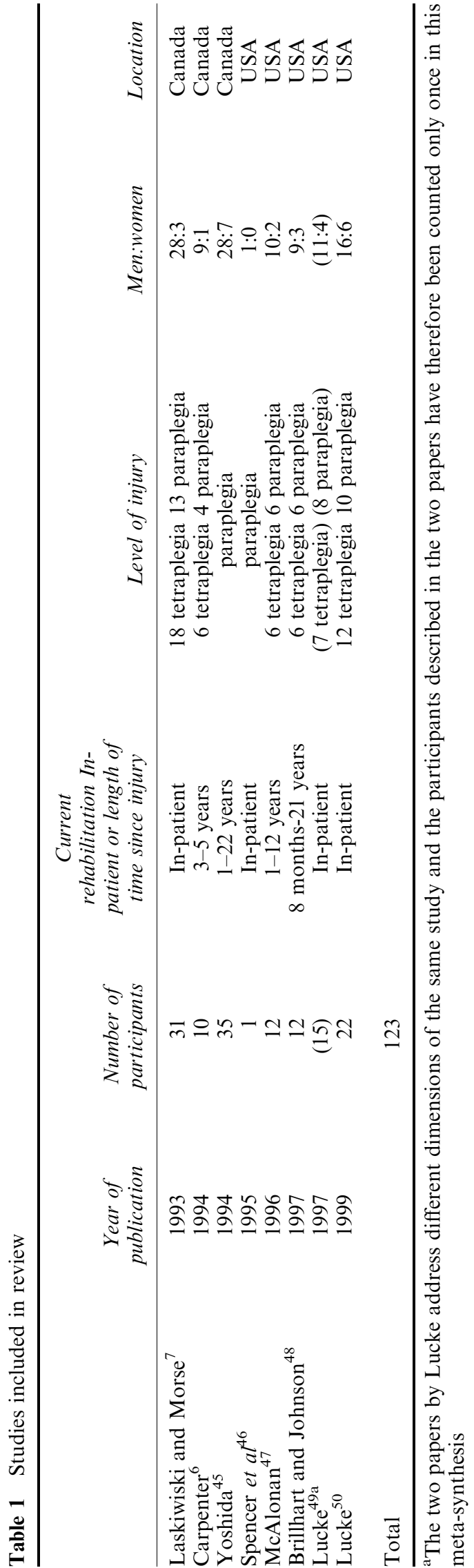

terminology. The key issues identified by the participants and their researchers were summarized using condensing labels (see Table 2).

\section{Comparison and synthesis of themes}

Labels summarizing themes identified in the previous phase of the study were listed in columns with other, similar or related themes. Through this process relationships were established between the data, resulting in the formation of seven concepts that synthesized the findings of the eight papers (see Table 2). These seven concepts, each of which was identified in at least six of the eight papers, are outlined in turn (below) using representative participants' data and the insights of the researchers. However, these concepts do not have rigid parameters but inter-relate with other concepts. Comments pertaining to the quality of staff, for example, can be seen to permeate every concept.

The importance of specific staff qualities The greatest number of comments concerning rehabilitation centred on those qualities of rehabilitation staff that were either valued or deplored. Study participants felt their selfesteem had been enhanced, ${ }^{49,50}$ their 'spirits lifted' and a sense of value and wholeness engendered ${ }^{50}$ by those staff members who treated them as unique people rather than rehabilitation clients. ${ }^{48}$ Staff who were perceived to have contributed positively to the process of rehabilitation following SCI were those who had treated each patient 'like a regular average person' rather than as physically 'different', ${ }^{48}$ who were perceived to be caring, who treated patients as partners in their rehabilitation $\operatorname{plan}^{49,50}$ and who had a direct, open style of communication. ${ }^{47}$ Patients with SCI felt respected and valued when staff shared both professional and personal information, ${ }^{47,49}$ included them in decision-making, ${ }^{49}$ achieved a 'caring' rather than a 'professional' environment ${ }^{48}$ and interacted with clients in a personal rather than professional manner. ${ }^{49}$ Patients appreciated staff who 'were genuinely caring, treated them as adults, were relaxed about the rules and regulations and shared personal information'?

Staff who were valued were those who asked patients what they wished to achieve, ${ }^{49}$ who assisted patients in thinking about the future, ${ }^{46}$ were comfortable with sexual concerns, ${ }^{47}$ enabled clients to meet experienced peers, ${ }^{50}$ encouraged patients to ask questions, ${ }^{47,48}$ worked in partnership with patients to solve problems, ${ }^{48}$ communicated respect for clients, encouraged independent thought and behaviour and adopted the role of consultant/collaborator as they enabled patients to assume responsibility for their own rehabilitation plans. ${ }^{50}$ Indeed, those staff who encouraged clients to be creative in solving problems were perceived to have conveyed a message that 'nothing was impossible'.50 Staff labelled as 'caring' and 'competent' were those who listened to patients and acknowledged their concerns, ${ }^{50}$ who endeavoured to learn about each patient as a 
Table 2 Summary of 7 concepts comprising themes identified through the synthesis

\begin{tabular}{|c|c|c|}
\hline Importance of specific staff qualities & Need to envision future life possibilities & Importance of peers \\
\hline 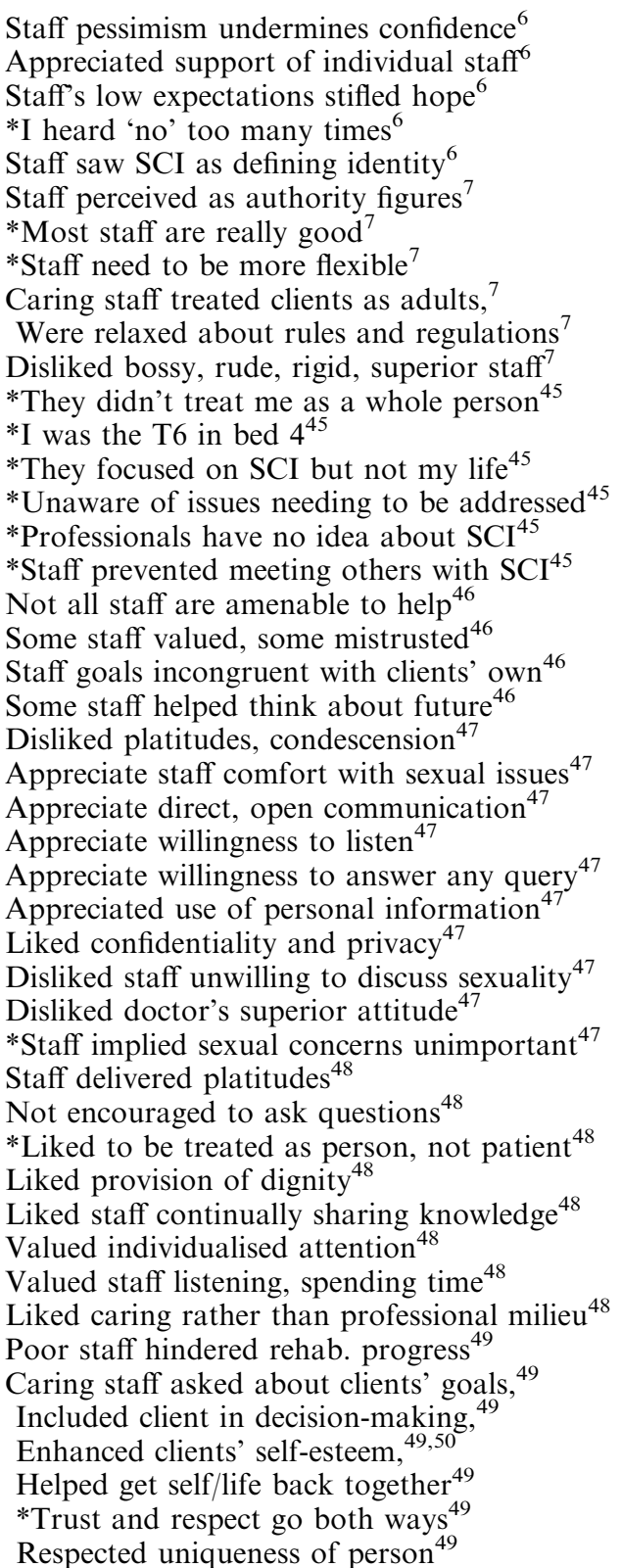 &  & 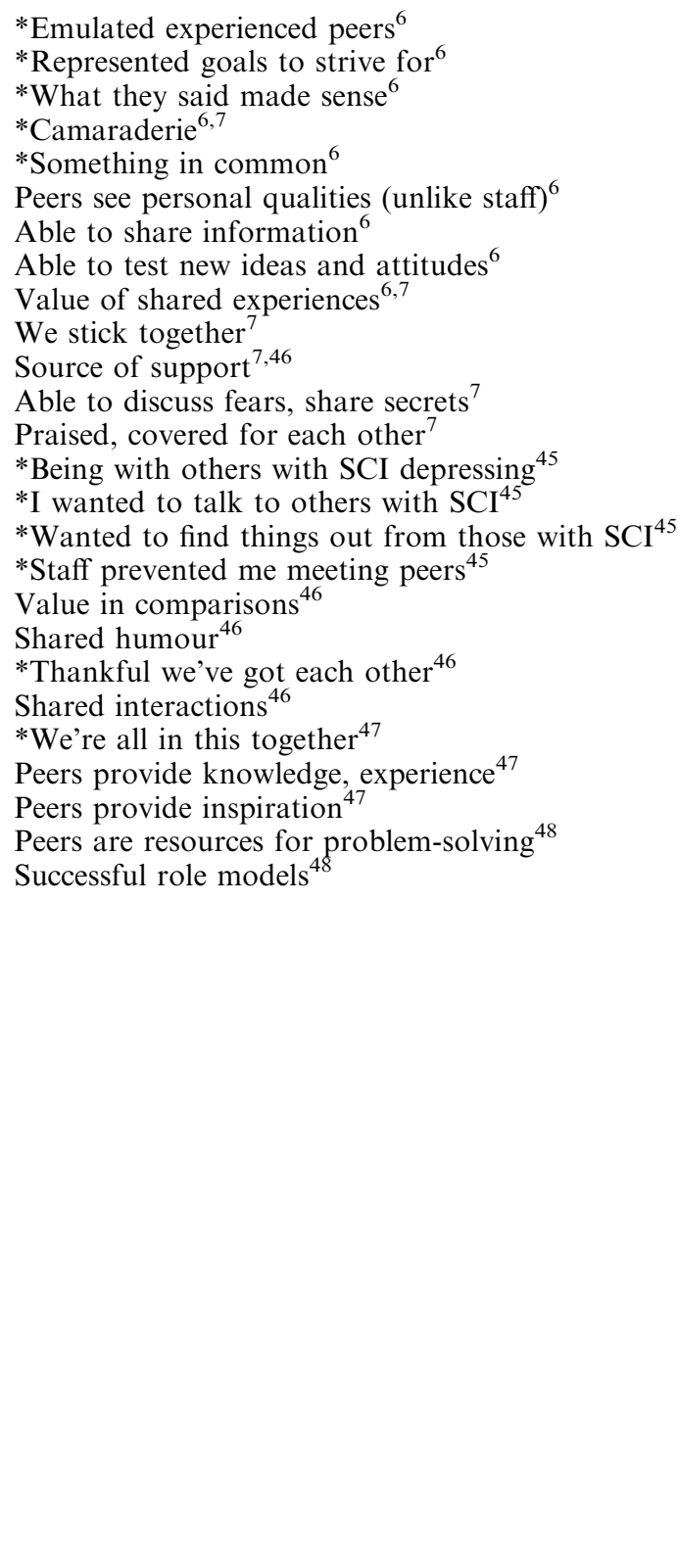 \\
\hline
\end{tabular}


Table 2 Continued

Importance of specific staff qualities

Need to envision future life possibilities

Importance of peers

Individualised care ${ }^{49}$

Transgressed institutional rules ${ }^{49}$

*Used humour sensitively ${ }^{49}$

Worked with clients as partners 49,50

*Let me make my own choices 49,50

Demonstrated mutual trust and respect ${ }^{49,50}$

*Shared on personal level ${ }^{49}$

Treated me as real person ${ }^{49}$

Engaged in creative problem-solving ${ }^{49,50}$

Led to enhanced motivation and hope ${ }^{50}$

*Lifted my spirits ${ }^{50}$

*Treated me as a human being ${ }^{50}$

*Took time to explain things

Enhanced feelings of dignity

*Gave positive feedback ${ }^{50}$

Facilitated access to experienced peers ${ }^{50}$

*Allowed us to try things ${ }^{50}$

*Maintained open dialogue $e^{50}$

Assumed role as consultant/collaborator ${ }^{50}$

Supported independent behaviour ${ }^{50}$

Showed genuine concern and listening ${ }^{50}$

Provided caring, supportive relationship ${ }^{50}$

Non-traditional care led to better outcomes ${ }^{49}$

Quicker outcomes ${ }^{49}$

*Feel of value as a unique human being ${ }^{49,50}$

Feelings of confidence ${ }^{5}$

Non-caring staff: were authoritarian ${ }^{50}$

Excluded clients from care meetings ${ }^{49}$

Defensive and angry if demands unmet ${ }^{49,50}$

Nagged $^{50}$

Showed little interest in client ${ }^{50}$

Caring $=$ knowledge, interpersonal skills ${ }^{50}$

Caring $=$ technical skill, competence ${ }^{50}$

Staff competence $=$ treating whole person ${ }^{49}$

Institutional context of rehabilitation

Content of rehabilitation

Importance of reconnecting the past to the future

Restrictive environment

${ }^{*}$ I was lucky to have well-trained people ${ }^{6}$

*Like being in jail/prison camp ${ }^{6,7,46}$

Separated from real world ${ }^{6}$

Rehab. driven by institutional constraints ${ }^{6}$

*Rehab. beset with policies and procedures ${ }^{6,7}$

Bureaucracy took precedence over clients ${ }^{6}$

Programmes dominated by bureaucracy ${ }^{6}$

Overly-structured

*Focused on physical skills ${ }^{6,45}$

*Methods taught as if only method ${ }^{6}$

Need to see independence $=$ self-determination ${ }^{6}$

Well-organised

Overly structured ${ }^{7}$

Time drags on evenings and weekends ${ }^{7}$

*Discouraged from expressing anger ${ }^{45}$

Focus on disabled self ${ }^{45}$

*Lack of attention to sexual concerns ${ }^{45}$
Need to connect past to future self ${ }^{6,46}$

* Rehab. helped me get back on track ${ }^{6}$

$*$ Old friends and family provided continuity ${ }^{6}$

Reconciling external and internal selves ${ }^{6}$

Need to define self by abilities and potential ${ }^{6}$

Had to challenge staff's low expectations ${ }^{6}$

Need to restore personal coherence 6

Need to adapt old interests ${ }^{6}$

Assimilation of disability into life continuum ${ }^{6}$ 
Table 2 Continued

Institutional context of rehabilitation

Inflexible schedule ${ }^{45}$

Schedules suit staff needs ${ }^{7}$

Time drags on evenings and weekends ${ }^{7}$

Regulated like imprisoned $/$ marginalised $^{7}$

Hard to find breathing room ${ }^{7}$

Staff too rigid; push us around ${ }^{7}$

*Staff need to treat us like human beings ${ }^{7}$

$*$ We were sheltered in rehabilitation ${ }^{45}$

*Too many restrictions ${ }^{45}$

*Staff dictate what you wear ${ }^{45}$

Institution strips away individuality ${ }^{4}$

Activities not scheduled in sensible way ${ }^{46}$

Routines don't make sense ${ }^{46}$

Standardised process of sequential steps ${ }^{45}$

Valued a homely environment ${ }^{48}$

Success due to caring staff ${ }^{49}$

Clients unable to attend goal-planning mtgs. ${ }^{49}$

Staff assigned according to procedures ${ }^{49}$

Homogenisation of a SCI identity ${ }^{50}$

Fragmentation of care ${ }^{50}$

Standardised approach ${ }^{50}$

Ignored individual needs ${ }^{45,50}$

*It's not easy living with these restrictions ${ }^{50}$

Importance of meeting the needs of the real world

Gaps between what was taught//required ${ }^{6,45}$

*So much to learn after I left ${ }^{6}$

*Things learned don't apply at home ${ }^{6}$

*Gap in information after leaving rehab. ${ }^{6}$

* Lack of preparation for real world ${ }^{6,45}$

Staff did not learn from former clients ${ }^{6,7}$

Staff unaware of real world needs

*No idea what you are going to face ${ }^{45}$

*Concerned about functioning in real world 45

Rehab. facility so accessible it's irrelevant ${ }^{45}$

*Needed to learn more/different skills ${ }^{45}$

Lack of social preparation ${ }^{45}$

*Not prepared for world beyond rehab. ${ }^{45}$

*Staff have no idea about living with $\mathrm{SCI}^{45}$

What will life be like? ${ }^{46}$

Good staff made skills relevant to reality ${ }^{49}$

Client-centredness enables quality of life $\mathrm{e}^{50}$
Content of rehabilitation

Lack of concern for individuality ${ }^{45,46}$

Lack of social preparation ${ }^{45}$

*Slow pace drives me crazy ${ }^{46}$

*Makes me feel useless, worthless ${ }^{46}$

Programmes and routines are standardised ${ }^{46}$

Staff had own agenda ${ }^{46}$

*I play the game of compliance ${ }^{46}$

Need to express emotions, not just physical ${ }^{47}$

Desire to include significant others

Inadequate information about sexual options ${ }^{47}$

Wish staff to be current on fertility research ${ }^{47}$

Wanted more peer counselors ${ }^{4}$

Appreciated individualised interventions ${ }^{48}$

Appreciated self-assessment/problem solving ${ }^{48}$

Goals established by staff ${ }^{49}$
Importance of reconnecting the past to the future

* My back is broken, nothing else

Changed body but same person ${ }^{7,48,49,50}$

Loss of self accentuated by staff focus on $\mathrm{SCI}^{45}$

*I wanted things to go on ${ }^{45}$

Lack of attention to nondisabled self ${ }^{45}$

Staff disregarded sexuality - nondisabled self ${ }^{45}$

Need to maintain continuity of biography ${ }^{45}$

*What person can I become?

Need to connect past to future ${ }^{46}$

Need to link past abilities to future possibilities ${ }^{46}$

Ability to continue former interests ${ }^{4}$

Work of rehabilitation $=$ reintegrating selves ${ }^{49,50}$

*Need to get self/life back together ${ }^{49}$

What from the past can I continue?

Positive sense of self results from caring staff ${ }^{50}$

*Need to get back together ${ }^{50}$

*Indicates those themes identified within participants' original data (as cited by researchers) 
person (including their strengths and goals), who strived to treat the whole person, respected the uniqueness of the individual, individualized care and 'broke the rules' to meet individuals' needs. ${ }^{49}$

Conversely, staff perceived as 'non-caring ${ }^{50}$ were those who delivered platitudes, ${ }^{47,48}$ nagged patients about their care routines, demonstrated little interest in the clients' progress and failed to help in solving problems. ${ }^{50}$ Non-caring staff were perceived to be those who demanded that things be done in certain ways and who became angry and defensive when clients failed to 'do what they were told'. ${ }^{50}$ These staff were considered authoritarian, 'bossy and rigid, were there only for the paycheck, had a superior attitude, and thought they knew everything' ${ }^{7}$ Consequently, patients refused to share important information with them. ${ }^{7}$ Some study participants felt their staff had not viewed them as whole people but, for example, as 'the T6 injury in bed $4{ }^{45}$ Importantly, those 'traditional' staff perceived to be non-caring were felt to have hindered the attainment of successful outcomes by their failure to understand the patient's needs, inability to create an atmosphere of trust in which questions could be asked and by their resistance to creative problem-solving. ${ }^{49}$ Patients disliked staff who had a superior manner or were unwilling to discuss sexuality. ${ }^{47}$

Patients complained of being 'assigned' staff rather than enabled to work with those members of staff with whom they were able to establish relationships based on mutual trust and respect. ${ }^{49}$

The need to envision future life possibilities The need to envision what sort of life might be possible with SCI was a recurring theme in all eight of the papers. This was expressed in terms of the following needs: for hope ${ }^{7,45,47,49,50}$ to envision possible options and opportunities ${ }^{45,46,48-50}$ and to anticipate a future that would be better than the present. ${ }^{48,50}$ As one person asked: 'what will life be like?" ${ }^{46}$ Although some study participants had appreciated the message conveyed during rehabilitation - that SCI might slow but not stop their lives ${ }^{48}$ - other rehabilitation services were perceived to have been wholly preoccupied with the limitations imposed by SCI, with staff invoking pessimistic expectations of abilities and potentials that had effectively stifled hope and undermined a sense of competence. ${ }^{6}$ Moreover, these predictions had often proved inaccurate: 'All the things they told me I couldn't do are proved wrong now'.

Although appreciating the support and assistance provided by individual staff, some study participants felt that rehabilitation professionals in general tended to regard SCI as a defining identity, failing to contest societal stereotypes that equate disability with inability. ${ }^{6}$ For example, when one man envisioned a future life with paraplegia in which he would only leave his home to buy groceries, this vision was neither challenged nor contradicted by rehabilitation personnel. ${ }^{46}$
Some people claimed that during the rehabilitation process they realized there could be 'life after spinal cord injury': that they could still have important relationships and resume meaningful and productive activities despite their injuries. ${ }^{48,50}$ Staff who enabled clients to understand: it is going to get better; there is life after paraplegia. It's different, but there's still something there $^{, 50}$ - who conveyed a sense of hope for the future were those who encouraged clients to talk of their former lives and priorities, acknowledged the importance of these issues and either shared what they had learned from others with SCI or referred their clients to an experienced peer with whom they could talk. ${ }^{50}$ Staff who engendered hope were those who asked patients what they wished to accomplish during rehabilitation, ascertained what was important to them and encouraged them to think towards the future. ${ }^{49}$ Notably, none of the study participants complained that rehabilitation staff had engendered too much hope or an unrealistically optimistic vision of a future life with SCI. Rather, 'being handicapped is a lesser problem than they led me to believe'. ${ }^{6}$

The importance of peers Patients with SCI had greatly valued their peers with SCI: those 'brothers in arms' ${ }^{6}$ or comrades $^{7}$ with whom they shared the rehabilitation experience; and those experts who had served as role models and exemplars of what can be achieved following SCI. ${ }^{48}$ Whilst patients, people with SCI had supported one another, ${ }^{7,46}$ discussed their problems and fears, covered up for each other, praised one another and shared secrets: 'we stick together because no one knows what it is really like to have a broken back unless you have gone through the same thing, ' "we're all in this together'. ${ }^{47}$ Patients felt that in comparison to rehabilitation staff, others with SCI were able to see beyond their physical impairments to more important dimensions of their identities. ${ }^{6}$ With their peers, people with SCI were able to share information and formulate ideas, ${ }^{6}$ although some people had initially found being with other people with SCI to be depressing. ${ }^{45,46}$

For many people with recent SCI, the opportunity to meet those who had already lived with SCI for many years was immensely important, providing valued resources for advice on problem solving ${ }^{48}$ providing knowledge, experience and inspiration. ${ }^{47}$ Even several years after these pivotal meetings, individuals recalled their impact on their lives and claimed that these peers served 'as a goal for us to strive for' and that what they said 'made sense'. ${ }^{6}$ For others, the lack of opportunity to meet experienced peers during rehabilitation was lamented: 'I wanted to talk to people who had been injured for a longer period of time to find out... what is it like when you leave the hospital?'. ${ }^{45}$ People said they had wanted to talk to others with SCI to find out, for example, what sort of wheelchair they had bought, and why; how they travelled, where they lived and why; what was accessible or not accessible in the city, and so forth. However, this expressed desire was sometimes 
thwarted by rehabilitation professionals: 'I wanted someone in a wheelchair to come and talk to me. And they would not let that happen because...they said...'these people (others with SCI) are not qualified professionals'. They said you are going to have to find out on your own'. ${ }^{4}$

The institutional context of rehabilitation Frequent concerns were expressed about the inflexible schedule of the rehabilitation process that restricted what people with SCI were allowed to wear and what they were permitted to watch on TV (eg the late evening news). ${ }^{45}$ 'Because they had to line up for food, patients with SCI said that the cafeteria reminded them of prison camp'. Their behaviour was 'regulated' and rehabilitation was equated with being 'imprisoned, deprived and underprivileged'. ${ }^{7}$ The rehabilitation facility was described as a restrictive environment: 'like being in jail', 'beset with policies and procedures' in which the demands of an institutional bureaucracy took precedence over the differing needs of individual patients. ${ }^{6}$ These same themes recurred across the studies, for example: 'It's just like a jail... You can't do nothing. You can't go nowhere'. 46

In some instances, patients had endeavoured to remind staff to be less rigid and protested their loss of freedom and control: 'I'm sick and tired of being pushed around and having to live with the rules in this $\mathrm{f}$...ing place'. ${ }^{7}$ Staff inflexibility and unwavering adherence to rules and regulations that governed every dimension of their lives were perceived to demonstrate an ignorance of what it was like 'to live here 24 hours a day'. Participants complained that their individuality was stripped away, 45 that they were assigned a homogenizing 'SCI identity' 50 and that the overly-structured,' inflexible schedules ${ }^{45}$ and standardized approaches to rehabilitation $^{45,50}$ had ignored individual needs. ${ }^{45,50}$ They had wished to be treated as 'human beings' with individual needs ${ }^{7,49,50}$ and not as a 'goddamn robot'.

The content of rehabilitation Some participants praised the individualized methods and problem-solving approaches that had been used to assess needs and teach daily living skills. ${ }^{48}$ However, most rehabilitation programmes were perceived to have been 'standardized', such that the issues addressed did not match the issues of expressed importance to clients, ${ }^{46}$ skills were not tailored to individuals ${ }^{7}$ and clients' individual needs were not met. ${ }^{45}$ Some patients had not been allowed to be present when rehabilitation goals were discussed and therefore had goals established for them. ${ }^{49}$ Staff were perceived to have their own agenda ${ }^{46}$ and the 'established routines' of the rehabilitation facilities were a frequent source of irritation, with the slow pace making patients feel 'useless, worthless...its driving me crazy just sitting here'. ${ }^{46}$ Patients had made suggestions as to how these routines could be made more efficient but soon learned to 'play the game' of compliance. ${ }^{46}$ Some rehabilitation programmes were perceived to have been well organized, such that days were 'busy', if 'overly structured', 7 however, on weekends and evenings 'time dragged, and patients had to make an effort to 'kill' time'. These constituted 'bad days': 'a bad day is when you have time to kill... Since I've been in this place, I... watch a hell of a lot of TV'?

Rehabilitation programmes were reportedly focused on 'physical stuff' such as muscle strengthening, self care skills 6,45 and the mechanics of sexual function, ${ }^{47}$ strongly discouraging any attempts to express emotions. ${ }^{45,47}$ Lack of attention to sexual concerns was also lamented, particularly because this appeared to convey the message that those with SCI were 'finished'. 45 Several people felt they were treated as if they were no longer men or women but a sort of neutered category: 'disabled' ${ }^{45}$ Patients expressed the desire to have their partners included in sexual counselling, wanted more peer counsellors and needed staff to be knowledgeable about current fertility research. ${ }^{47}$

The importance of meeting the needs of the real world Critical gaps were perceived between the skills taught during rehabilitation and those needed in the 'real world'. 6,45 Some new skills proved to be inapplicable outside the rehabilitation setting and others were taught as if they were the only way to accomplish a task, rather than simply one of many possibilities. ${ }^{6,45}$ For some, there had been a 'total lack of information' about what would be required following discharge ${ }^{6}$ such that 'you have no idea what you are going to face later'. 45 People with SCI identified a lack of preparation for the real world as one of the major omissions of the rehabilitation process. ${ }^{6}$ Indeed, it was felt by some that the rehabilitation programme had done little more than teach people to function within a rehabilitation environment. 45

Some study participants had benefited from staff who discussed with patients how various self-care tasks would fit into their routines once they returned home: seeking to connect skills to the contexts in which they would be needed. ${ }^{49}$ Others felt that rehabilitation staff knew very little about their work: 'Nothing against your profession (physiotherapy) but you people know f $\cdots$ all about what it is like to go through (SCI)'. ${ }^{45}$ Staff members rarely saw former patients and their families following community discharge and therefore had no knowledge of their lives or accomplishments, ${ }^{7}$ demonstrating little effort to learn from those who had already learned to live well with SCI. ${ }^{6}$ Thus, what the rehabilitation professionals had not covered during rehabilitation, 'they probably did not know about'. ${ }^{45}$

The importance of reconnecting the past to the future Although patients became aware that 'their bodies were changed, but not their minds, nor their identities ${ }^{, 7,48-50}$ with injury the body/self relationship had suddenly become more complex, and this was an important theme 
in seven of the papers. Carpenter ${ }^{6}$ identified an 'experiential split' between what she termed the 'external' and 'internal' selves. She used the idea of the external self to connote the alterations in body image and physical function resulting from the SCI, whereas the internal self represented the accumulated life history and experience of the person. Yoshida ${ }^{45}$ and Lucke ${ }^{49,50}$ identified the same issues but termed these the disabled and nondisabled selves, ${ }^{45}$ and physical and inner selves, respectively. ${ }^{49,50}$ Lucke $^{49,50}$ concluded from her study that the 'major work' of rehabilitation following SCI is 'getting back together' or 'reintegrating the self'. The perceived need to connect a future life with a SCI to a past life of interests, relationships, skills and competencies - to get life 'back on track' ${ }^{6}$ - was a recurring theme, ${ }^{6,45,46,49,50}$ - yet staff frequently discouraged patients from thinking about the future and issues such as paid employment. ${ }^{46}$ People felt unable to prepare for the future because they were unable to foresee what their futures might, or could be. ${ }^{6,45}$ Rehabilitation services were perceived to have focused wholly on the physical self, treating the SCI but not the person who had sustained the SCI. ${ }^{45}$ By failing to connect the changed physical self to the unchanged internal self, rehabilitation was perceived to have failed to enable people with SCI to incorporate their physical changes into an ongoing life $\mathrm{f}^{6,45}$ or to have restored a sense of personal coherence. $^{6}$

\section{Discussion}

This study demonstrates the utility of the meta-synthesis in assembling and surveying existing qualitative knowledge on a specific issue. Although few researchers have sought to probe the experience of rehabilitation following SCI, this review has attempted to accumulate the knowledge currently available in existing studies. Through a process of comparison the review found that people with SCI expect to be enabled to envision a future life of possibilities and opportunities, and to anticipate a future self that is continuous with the 'old' self, rather than defined by SCI. The degree to which rehabilitation services assist in this endeavour appears to be influenced by the institutional context (including specific staff qualities, programme content and its applicability to the needs of the 'real' world), and by the involvement of peers. These are interlinked and interdependent concepts.

It is important to acknowledge that rehabilitation, by definition, occurs during an unwelcome phase in a life disrupted by a severe injury and is a time of profound uncertainty and struggle. However, despite the reality that the 123 people included in this synthesis ranged from those still undergoing in-patient rehabilitation $^{7,46,49,50}$ to those who had lived for several ${ }^{6,45,47,48}$ or many $45,47,48$ years since injury, it did not appear that the passage of time had softened the more negative appraisals of the rehabilitation experience, nor served to persuade these former patients of the relevance and merit of their various rehabilitation programmes. Nor did it appear that those rehabilitation services experienced in recent years were appraised more favourably than those of previous decades. Alternatively, it might be expected that people who were still in-patients at the time of study might view their rehabilitation services more favourably because they would be unaware of any mismatch between the skills being taught and those subsequently required to function in a 'real world' setting. In reality, there is little discernable difference between the reports of current in-patients and those of people living in the community, although the latter group had considerably more to say than the former about the lack of preparation they had received for living in the real world.

\section{Hope: envisioning a meaningful future}

Researchers have recognized the importance of hope in the rehabilitation process following SCI. 7,43,44,50 'Hope', in this context, has been defined as 'knowing there is life that can be productive and meaningful after spinal cord injury $^{, 50}$ (page no. 251). Each of the studies included in this review identified the need for rehabilitation professionals to foster a hopeful vision of life with SCI, focused on capabilities rather than inabilities. This supports the findings of previous researchers. ${ }^{8-10}$

Frank $^{51}$ (page no. 159) suggested that after the initial shock of a diagnosis has dulled somewhat, the individual must surely consider, 'What do you wish to become in this experience?'. Researchers have suggested that people with SCI wish to envision a 'future self in action in a way that makes life enjoyable and meaningful once again ${ }^{, 52}$ (page no. 297). However, Duggan et $a l^{53}$ (page no. 114) observed that adjustment to SCI can be difficult 'because there is no readily retrievable template upon which to anchor expectations for the future life course'. A 'template' or 'cultural narrative' constitutes a sort of script that frames the imagined life prospects for a member of a particular group, shaping the expectations and visions of what sort of life might be possible for someone 'like me'.

Cultural 'common-sense' speculates that a life with SCI is not worth living and this view tends to be shared, rather than contested, by health-care professionals, ${ }^{54-56}$ who often strive to reduce clients' expectations to match their own. ${ }^{57,58}$ This contributes to the perception that therapists share a pessimistic, negative and deflating ethos; ${ }^{11,59}$ a perception echoed in the study by Carpenter, ${ }^{6}$ who noted that because health-care professionals reflected societal stereotypes about disability they exhibited devaluing attitudes toward the capabilities and potential of their clients with SCI. Hutchinson and Kleiber $^{60}$ suggest that rehabilitation professionals need to challenge traditional stereotypes and provide people with SCI with alternative 'frames' or scripts by which they can see themselves and their future possibilities in new and expanded ways. Involving experienced peers in rehabilitation provides a realistic template of life possibilities for both newly injured people and rehabilitation staff. ${ }^{6,45}$ 
The content of rehabilitation programmes

Through this meta-synthesis three fundamental problems with traditional rehabilitation programmes have been identified: a preoccupation with the physical dimension of SCI; a lack of attention to individuality; and a failure to prepare clients to meet the needs of the real world.

The physical dimension of SCI Crewe ${ }^{61}$ claimed that people who make a good adjustment to SCI are those who can redefine their values, broaden the range of things that are cherished and decrease the emphasis on physique as a measure of the self, a finding supported by other researchers. ${ }^{6,62-64}$ This is inconsistent, however, with the preoccupation with physique, physical function and physical independence that characterizes traditional rehabilitation programmes. ${ }^{6,10,14,45,65,66}$ It is argued that because rehabilitation professionals have largely failed to challenge cultural narratives that revere physical prowess and that devalue the physically 'different', they have tended to promote an idealized prototype of success following SCI - the heroic action figure for whom physique is the prime measure of the self $-\mathrm{a}$ prototype that effectively limits the possibilities for future lives, value enlargement or personal growth. ${ }^{60,67,68}$ Further, this ideology leads to a rehabilitation environment in which physical independence and athletic accomplishments become idealized. Seymour ${ }^{14}$ claims that many people with severe impairments are 'damaged' and 'disenfranchized' by the predominance in rehabilitation of this ideology, an ideology that obscures other avenues of potential and ability and overlooks the needs of women, older people and those with high lesions. Moreover, Kleiber and Hutchinson $^{67}$ (page no. 135) contend that vigorous physical activity and sport, so prominent in rehabilitation settings, are 'at best a temporary palliative to the 'crisis' of physical disability' for men with SCI and at worst, an impediment both to the development of other ways of expressing masculinity and of enlarging the range of valued dimensions of the self. Indeed, Seymour $^{14}$ (page no. 124) argues that to encourage people with disabilities to imitate the values of the world of able-bodied men is to set them up for failure'. Thus, although researchers have concluded that adjustment to disability is more difficult for men who adhere to dominant cultural stereotypes of masculinity, ${ }^{14,68,69}$ this is the constraining 'script' that tends to be promoted in rehabilitation. ${ }^{67,68,70}$

Further, an emphasis on physique, physical function and physical independence focuses primarily on the 'disabled' self. ${ }^{45}$ This obscures the reality that although SCI is part of someone's life, it is not the whole. ${ }^{6}$ Rehabilitation, it is argued, should not be about people's bodies, but about their lives. ${ }^{14,71}$ In reality, however, 'institutions and environments are not awash with counter-narratives on which to build alternative identities, notions of self and forms of embodiment ${ }^{68}$ (page no. 624). It is apparent that both patients and clinicians need to envision a diversity of templates for ways of living with $\mathrm{SCI}^{72}$ and that they can do so by learning from the peer group of experts who have already lived successfully for several years with SCI.

Attention to individuality The findings of this metasynthesis support those of other researchers who have noted the inappropriateness and ineffectiveness of a 'one size fits all' approach to rehabilitation following SCI and who have advised replacing 'standardized' programmes, ${ }^{46,50}$ 'standard procedures'13 and 'inflexible schedules ${ }^{45}$ with an individualized, tailored approach in which clients work in partnership with their therapists. ${ }^{6,13,48}$ Lucke $^{49}$ (page no. 94) observed: 'In an era of managed care where standardization is encouraged, patients remind us that it is through individualized care that effective and efficient outcomes are achieved'. Researchers have demonstrated that when patients are actively involved in making decisions, have their perspectives and goals acknowledged and their questions answered they not only become more knowledgeable about their conditions but are more committed to participate in therapy, express more confidence in the competence of those providing care and greater satisfaction with the therapeutic process and outcome. ${ }^{73-75}$ But is an individualized approach to rehabilitation feasible, practical and affordable? Researchers report that a client-centred approach leads to improved outcomes, such as shorter hospital stays, reduced symptoms, reduced anxiety, greater sense of control and satisfaction, better goal attainment, greater adherence to treatment plans, and statistically and clinically significant gains in clients' abilities to perform or direct selfcare and community living skills. ${ }^{75-79}$ Moreover, time and resources are optimized when attention is focused on those issues of greatest importance to the client. ${ }^{80}$ Although it might be argued that institutional demands for rapid throughputs and standardized efficiencies can militate against an individualized, needs-led approach to rehabilitation for people with SCI, the fact that the participants in the reviewed studies cited so many examples of practice excellence suggests that accountability and compassion are not inherently incompatible.

Preparing clients to meet the needs of the real world In six of the studies in the review, participants lamented the lack of preparation they had received ${ }^{6,45}$ or were receiving ${ }^{7,46,49,50}$ to meet the needs of the world outside the rehabilitation facility. Researchers have reported that people undergoing rehabilitation following SCI wish to meet others who have already learned to live with SCI so that they can begin to learn what skills they will require to function, both socially and physically, in a world designed to meet the needs of the dominant, non-disabled population. ${ }^{6,45,47,48,64}$ Carpenter $^{6}$ claimed that health-care professionals also need to learn about the lives of people who have lived for several years with SCI in an effort to narrow the gap between what is 
offered by rehabilitation services and what is actually relevant in the 'real world': 'learning from their experiences may assist us to develop more relevant programs' (page no. 627). ${ }^{6}$

\section{Reconnecting: past and future lives, past and present selves}

SCI disrupts both an ongoing life and a sense of self, $6,45,49,50,64,70,81-83$ thus rehabilitation is more than a physical endeavour: it is not just about treating a body, but about addressing the needs of a life. ${ }^{71}$ The findings of this review suggest that it is important to patients to be able to connect their past with their future, to attain a sense of continuity and to be able to envision a future self. $^{6,45,46,84}$ Toombs $^{85}$ (page no. 351) argued that 'an important therapeutic goal is to assist those faced with physical disability in their efforts to reconstruct or redefine their changed selves. Indeed, to ignore the transformation of the self is to discount the major impact of disability'. Rehabilitation's traditional preoccupation with the physical body addresses only part of the body/self equation and constitutes, at best, a partial response to SCI. ${ }^{71}$

Thompson et $a l^{86}$ proposed that people who have sustained a life-disrupting injury, such as SCI, need to find a new 'I am' as well as a new 'I can'. To date, however, rehabilitation has focused entirely upon the 'I can' - fostering abilities and facilitating functions but has paid scant attention to re-defining 'who I am' in the face of impairment. ${ }^{71}$ In this way, rehabilitation reflects an ideological dualism in which the physical body is construed as somehow extrinsic to the self. Indeed, the self appears of little concern in the therapeutic endeavour. ${ }^{85}$ Toombs $^{85}$ (page no. 356) observed that 'one does not simply RESUME life, following the onset of disability; one reconstitutes selfidentity in integrating one's changed way of being into a new life plan'. This is, arguably, the essence of the rehabilitation enterprise.

\section{The institutional context of rehabilitation}

The findings of this meta-synthesis support those of other researchers who have identified the dehumanizing impact of those restrictive rules and rigid procedures that govern the provision of rehabilitation services. ${ }^{10,13}$ The 'institutional' dimensions of an environment include those policies, decision-making processes, procedures, organizational practices, financial priorities and services that impact on the individual. ${ }^{87}$ In this review, rehabilitation services were described as 'homogenizing', 50 'inflexible', 45 'regulated', 'restrictive' ${ }^{6}$ environments 'beset with policies and procedures' ${ }^{\prime}$ such that clients described themselves as being imprisoned, deprived and underprivileged'?

Carpenter $^{6}$ (page no. 21) claimed that rehabilitation 'continues to be driven by the expectations... of health professionals and the constraints of the institutional organization'. Staff inflexibility and unwavering adher- ence to rules and regulations ${ }^{7}$ was found to be integral to the rehabilitation process. Indeed, institutional practices are inseparable from those staff who willingly reinforce and reinscribe them. ${ }^{71}$

\section{Rehabilitation personnel}

The greatest number of comments cited in the eight papers pertained to the quality of rehabilitation staff and it was evident that staff held the power to facilitate or to thwart the process of reconstructing life in an altered physical form. The findings of this review support existing evidence that rehabilitation clients desire therapists who choose closeness over distance and detachment, who demonstrate respect for clients, who create supportive and accepting relationships with clients, and who are kind. ${ }^{88,89-93}$ Clients value those therapists who strive to reduce power inequalities and to work in collaboration with clients; who are neither authoritarian nor judgemental, do not tell their clients what to do and who work on behalf of, for and with clients towards those goals that are identified by, and of importance to clients. ${ }^{49,88,89,91,92}$ Moreover, research demonstrates that when people are respected as equals they feel involved in their rehabilitation, inspired and motivated, and experience enhanced feelings of self-worth and self-esteem. ${ }^{58,89,90}$

Indeed, while the health-care professions foster and reward academic and technical excellence and social conformity, ${ }^{71}$ what patients appear to value most in their therapists is a sense of being valued as a human being. $59,88,90$

\section{Limitations}

Because this meta-synthesis drew exclusively upon papers written in English-speaking countries, no attempt can be made to generalize its findings to the majority of the world, whose cultural norms and values may result in very different experiences of rehabilitation following SCI. Further, because only one paper ${ }^{47}$ provided any information concerning the percentage of respondents who were satisfied or dissatisfied with their rehabilitation it is impossible to determine whether the data on which this study was based has resulted in a misleadingly optimistic or pessimistic perspective of the experience of rehabilitation following SCI.

\section{Conclusion}

If rehabilitation services are to be evidence-based, relevant and effective in meeting the needs of people with SCI, they must be informed by the perspectives of those people who have experience of both SCI and rehabilitation: people with SCI. Although surprisingly little research has explicitly sought to explore the experience of rehabilitation following SCI, this metasynthesis has drawn together the insights of 123 people with SCI, cited in eight papers (seven studies) and has identified seven common themes: the importance of 
quality staff, and the importance of expert peers; the institutional context of rehabilitation, and actual programme content; the need for a hopeful vision of future life possibilities; the importance of reconnecting the past to the future, and of meeting the needs of the real world.

Notably, no data addressed the physical environment of rehabilitation: the benefits (or lack) of prestigious, state-of-the-art buildings, large gymnasia, extensive sporting facilities, high-tech gadgetry or well-equipped therapy areas. However, the importance of caring and visionary staff recurred throughout every study. These valued professionals were not slavish adherents to institutional rules and regulations, nor supporters of standard treatment templates but were those who strived to tailor their programmes to meet the realworld needs, interests and priorities of their individual clients and who enabled their clients to incorporate their physical changes into an ongoing life. These were people whose on-going commitment to learn about SCI from those who have already learnt how to live well with SCI, and to enabling their clients to learn from these experienced peers, who enabled them to hold out a hopeful vision for a life with SCI.

Indeed, the findings of this meta-synthesis suggest that if financial resources were allocated according to the priorities of rehabilitation clients (in accordance with current edicts ${ }^{1-5}$ ) these would be targeted, not at buildings, facilities or equipment but at the recruitment and retention of a substantial number of caring, clientorientated staff.

\section{References}

1 Twible RL. Consumer participation in planing health promotion programmes: a case study using the nominal group technique. Aust Occup Ther J 1992; 39: 13-18.

2 Clark C, Scott E, Krupa T. Involving clients in programme evaluation and research: a new methodology. Can J Occup Ther 1993; 60: 192-199.

3 NHS Executive. Rehabilitation: A Guide. Department of Health: Leeds 1997.

4 NHS Executive. Patient and Public Involvement in the New NHS. Department of Health: London 1999.

5 Cusack L, Sealey-Lapeš C. Clinical governance and user involvement. B J Occup Ther 2000; 63: 539-546.

6 Carpenter C. The experience of spinal cord injury: The individual's perspective - implications for rehabilitation practice. Phys Ther 1994; 74: 614-629.

7 Laskiwski S, Morse JM. The patient with spinal cord injury: the modification of hope and expressions of despair. Can J Rehabil 1993; 6: 143-153.

8 Corbet B. Bully pulpit: bound for glory. New Mobility 2000; 11: 4

9 Hammell KW. From the neck up: quality in life following high spinal cord injury. PhD thesis. University of British Columbia: Vancouver, Canada 1998.

10 Morris J. Able Lives. Women's Experience of Paralysis. Women's Press: London 1989.

11 Cant R. Rehabilitation following a stroke: a participant perspective. Disabil Rehabil 1997; 19: 297-304.

12 Lewinter M, Mikkelsen S. Patients' experience of rehabilitation after stroke. Disabil Rehabil 1995; 17: 3-9.
13 Oliver M, Zarb G, Silver J, Moore M, Salisbury V. Walking into Darkness. The Experience of Spinal Cord Injury. Macmillan: Basingstoke 1988.

14 Seymour W. Remaking the Body. Rehabilitation and Change. Routledge: London 1998.

15 Popay J, Williams G. Qualitative research and evidencebased healthcare. J Roy Soc Med 1998; 91(Suppl 35): 32-37.

16 Hammell $\mathrm{KW}$. Using qualitative research to inform the client-centred evidence-based practice of occupational therapy. Br J Occup Ther 2001; 64: 228-234.

17 Estabrooks CA, Field PA, Morse JM. Aggregating qualitative findings: an approach to theory development. Qual Health Res 1994; 4: 503-511.

18 Sandelowski M, Docherty S, Emden C. Qualitative metasynthesis: issues and techniques. Res Nurs Health 1997; 20: 365-371.

19 Mays N, Pope N. Quality in qualitative health research. In: Pope C, Mays N (eds). Qualitative Research in Health Care. BMJ: London 2000, pp 89-101.

20 Campbell $\mathrm{R}$ et al. Evaluating meta-ethnography: a synthesis of qualitative research on lay experiences of diabetes and diabetes care. Soc Sci Med 2003; 56: 671-684.

21 Sandelowski M. Rigor or rigor mortis: the problem of rigor in qualitative research revisited. Adv Nurs Sci 1993; 16: 1-8.

22 Morse J. Qualitative verification. In: Morse J, Swanson J, Kuzel A (eds). The Nature Of Qualitative Evidence. Sage: London 2001, pp 203-220.

23 Noblit GW, Hare RD. Meta-Ethnography: Synthesizing Qualitative Studies. Sage: London 1988.

24 Hammell KW. Quality of life after spinal cord injury: a meta-synthesis of qualitative findings. Spinal Cord 2007; 45: 124-139.

25 Jensen LA, Allen MN. A synthesis of qualitative research on wellness-illness. Qual Health Res 1994; 4: 349-369.

26 Jensen LA, Allen MN. Meta-synthesis of qualitative findings. Qual Health Res 1996; 6: 553-560.

27 Popay J, Rogers A, Williams G. Rationale and standards for the systematic review of qualitative literature in health services research. Qual Health Res 1998; 8: 341-351.

28 Dixon-Woods M, Fitzpatrick R. Qualitative research in systematic reviews. BMJ 2001; 323: 765-766.

29 Law M, Stewart D, Letts L, Pollock N, Bosch J, Westmorland M. Guidelines for critical review of qualitative research 1998. Available at http://www.fhs.mcmaster.ca/ $\mathrm{rehab} / \mathrm{ebp} /$.

30 Baxter J, Eyles J. Evaluating qualitative research in social geography: establishing 'rigour' in interview analysis. Trans Inst Br Geog 1997; 22: 505-525.

31 Hammell KW. Informing client-centred practice through qualitative inquiry: evaluating the quality of qualitative research. Br J Occup Ther 2002; 65: 175-184.

32 Hammersley M. What's Wrong With Ethnography?. Routledge: London 1992.

33 Sandelowski M. The problem of rigor in qualitative research. Adv Nurs Sci 1986; 8: 27-37.

34 Lincoln YS, Guba EG. Naturalistic Inquiry. Sage: Beverley Hills, CA 1985.

35 Robson C. Real World Research. A Resource for Social Scientists and Practitioner-Researchers. Blackwell: Oxford 1993.

36 Carpenter C, Hammell KW. Evaluating qualitative research. In: Hammell KW, Carpenter C, Dyck I (eds). Using Qualitative Research. A Practical Introduction for Occupational and Physical Therapists. Churchill Livingstone: Edinburgh 2000, pp 107-119. 
37 Kirsch GE. Ethical Dilemmas in Feminist Research. The Politics of Location, Interpretation and Publication. State University of New York Press: Albany, NY 1999.

38 Barclay L. Exploring the factors that influence the goal setting process for occupational therapy intervention with an individual with spinal cord injury. Aust Occup Ther $J$ 2002; 49: 3-13.

39 Creighton C, Dijkers M, Bennett N, Brown K. Reasoning and the art of therapy for spinal cord injury. Am J Occup Ther 1995; 49: 311-317.

40 Rintala DH, Young ME, Spencer JC, Bates PS. Family relationships and adaptation to spinal cord injury: a qualitative study. Rehabil Nurs 1996; 21: 67-74.

41 Bates PS, Spencer JC, Young ME, Rintala DH. Assistive technology and the newly disabled adult: adaptation to wheelchair use. Am J Occup Ther 1993; 47: 1014-1021.

42 Newman JA, Reed BJ. Mexican-American males with a spinal cord injury. SCI Psychosoc Process 1998; 11: 14-19.

43 Lohne V, Severinsson E. Hope and despair: the awakening of hope following acute spinal cord injury - an interpretive study. Int J Nurs Stud 2004; 41: 881-890.

44 Lohne V, Severinsson E. Hope during the first months after acute spinal cord injury. $J$ Adv Nurs 2004; 47: 279-286.

45 Yoshida KK. Institutional impact on self-concept among persons with spinal cord injury. Int J Rehabil Res 1994; 17: 95-107.

46 Spencer J, Young ME, Rintala DH, Bates S. Socialization to the culture of a rehabilitation hospital: an ethnographic study. Am J Occup Ther 1995; 49: 53-62.

47 McAlonan S. Improving sexual rehabilitation services: The patient's perspective. Am J Occup Ther 1996; 50: 826-834.

48 Brillhart B, Johnson K. Motivation and the coping process of adults with disabilities: a qualitative study. Rehabil Nurs 1997; 22: 249-256.

49 Lucke KT. Knowledge acquisition and decision-making: spinal cord injured individuals perceptions of caring during rehabilitation. SCI Nurs 1997; 14: 87-95.

50 Lucke KT. Outcomes of nurse caring as perceived by individuals with spinal cord injury during rehabilitation. Rehabil Nurs 1999; 24: 247-253.

51 Frank AW. The Wounded Storyteller. Body, Illness and Ethics. University of Chicago Press: Chicago 1995.

52 Kleiber DA, Brock SC, Lee Y, Datillo J, Caldwell L. The relevance of leisure in an illness experience: realities of spinal cord injury. J Leis Res 1995; 27: 283-299.

53 Duggan $\mathrm{CH}$, Lysack C, Dijkers M, Jeji T. Daily life in a nursing home: impact on quality of life after a spinal cord injury. Topics Spinal Cord Inj Rehabil 2002; 7: 112-131.

54 Bach JR, Tilton MC. Life satisfaction and well-being measures in ventilator assisted individuals with traumatic tetraplegia. Arch Phys Med Rehabil 1994; 75: 626-632.

55 Gerhart KA, Koziol-McLain J, Lowenstein SR, Whiteneck GG. Quality of life following spinal cord injury: knowledge and attitudes of emergency care providers. Ann Emerg Med 1994; 23: 801-812.

56 deLateur BJ. Quality of life: a patient-centered outcome. Arch Phys Med Rehabil 1997; 78: 237-239.

57 Abberley P. Disabling ideology in Health and Welfare: the case of occupational therapy. Disabil Soc 1995; 10: 221-232.

58 Johnson R. 'Attitudes don't just hang in the air...': Disabled people's perceptions of physiotherapists. Physiotherapy 1993; 79: 619-627.

59 Corring D, Cook J. Client-centred care means that I am a valued human being. Can J Occup Ther 1999; 66: 71-82.
60 Hutchinson SL, Kleiber DA. Heroic masculinity following spinal cord injury: implications for therapeutic recreation practice and research. Therap Rec $J$ 2000; First quarter: $42-54$.

61 Crewe NM. Gains and losses due to spinal cord injury: views across 20 years. Topics Spinal Cord Inj Rehabil 1996; 2: $46-57$.

62 Keany KC, Glueckauf RL. Disability and value change: an overview and reanalysis of acceptance of loss theory. Rehabil Psychol 1993; 38: 199-210.

63 McMillen JC, Cook CL. The positive by-products of spinal cord injury and their correlates. Rehabil Psychol 2003; 48: 77-85.

64 Hammell KW. Quality of life among people with high spinal cord injury living in the community. Spinal Cord 2004; 42: 607-620.

65 Trieschmann RB. Spinal Cord Injuries - Psychological, Social and Vocational Rehabilitation, 2nd edn. Demos Publications: New York 1988.

66 Coyle CP, Lesnik-Emas S, Kinney WB. Predicting life satisfaction among adults with spinal cord injuries. Rehabil Psychol 1994; 39: 95-111.

67 Kleiber DA, Hutchinson SL. Heroic masculinity in the recovery from spinal cord injury. In: Sparkes A, Silvennoinen M (eds). Talking Bodies: Men's Narratives of the Body and Sport. University of Jyväskylä: Jyväskylä, Finland SoPhi 1999, pp 135-155.

68 Smith B, Sparkes A. Men, sport, and spinal cord injury: an analysis of metaphors and narrative types. Disabil Soc 2004; 19: 613-626.

69 Gerschick TJ, Miller AS. Coming to terms. Masculinity and physical disability. In: Sabo D, Gordon D (eds). Men's Health and Illness. Sage: London 1995, pp 183-204.

70 Sparkes A, Smith B. Disrupted selves and narrative reconstructions. In: Sparkes A, Silvennoinen M (eds). Talking Bodies: Men's Narratives of the Body and Sport. University of Jyväskylä: Jyväskylä, Finland, SoPhi 1999, pp 76-92.

71 Hammell KW. Perspectives on Disability and Rehabilitation: Contesting Assumptions, Challenging Practice. Churchill Livingstone: Edinburgh 2006.

72 Duggan $\mathrm{CH}$, Dijkers M. Quality of life - peaks and valleys: a qualitative analysis of the narratives of persons with spinal cord injuries. Can J Rehabil 1999; 12: 181-191.

73 Steele DJ, Blackwell B, Guttman M, Jackson T. The activated patient: Dogma, dream or desideratum? Patient Educ Couns 1987; 10: 3-23.

74 van Bennekom C, Jelles F, Lankhorst G, Kuik D. Value of measuring perceived problems in a stroke population. Clin Rehabil 1996; 10: 288-294.

75 Ford S, Schofield T, Hope T. What are the ingredients for a successful evidence-based patient choice consultation? A qualitative study. Soc Sci Med 2003; 56: 589-602.

76 Charles C, Gafni A, Whelan T. Shared clinical decisionmaking in the medical encounter: what does it mean? (Or it takes at least two to tango). Soc Sci Med 1997; 44: 681-692.

77 Guadagnoli E, Ward P. Patient participation in decisionmaking. Soc Sci Med 1998; 47: 329-339.

78 Neistadt M. Methods of assessing clients' priorities: A survey of adult physical dysfunction. Am J Occup Ther 1995; 49: 428-436.

79 Towle A, Godolphin W. Framework for teaching and learning informed shared decision making. BMJ 1999; 319: 766-769. 
80 Law M. Does client-centred practice make a difference? In: Law M (ed). Client-Centered Occupational Therapy. Slack: Thorofare, NJ 1998, pp 19-27.

81 Yoshida KK. Reshaping of self: a pendular reconstruction of self and identity among adults with traumatic spinal cord injury. Sociol Health Illn 1993; 15: 217-245.

82 Sparkes A, Smith B. Sport, spinal cord injury, embodied masculinities, and the dilemmas of narrative identity. Men Masculinities 2002; 4: 258-285.

83 Levins SM, Redenbach DM, Dyck I. Individual and societal influences on participation in physical activity following spinal cord injury: a qualitative study. Phys Ther 2004; 84: 496-509.

84 Lee Y, Datillo J, Kleiber DA, Caldwell L. Exploring the meaning of continuity of recreation activity in the early stages of adjustment for people with spinal cord injury. Leis Sci 1996; 18: 209-225.

85 Toombs SK. Disability and the self. In: Brinthaupt TM, Lipka RP (eds). Changing the Self: Philosophies, Techniques and Experiences. SUNY Press: Albany, NY 1994, pp 337-357.

86 Thompson NJ, Coker J, Krause JS, Henry E. Purpose in life as a mediator of adjustment after spinal cord injury. Rehabil Psychol 2003; 48: 100-108.
87 Canadian Association of Occupational Therapists. Enabling Occupation. An Occupational Therapy Perspective. Author: Ottawa, ON 2002.

88 French S. Enabling relationships in therapy practice. In: Swain J, Clark J, Parry K, French S, Reynolds F (eds). Enabling Relationships in Health and Social Care. Butterworth-Heinemann: Oxford 2004, pp 95-107.

89 Blank A. Clients' experience of partnership with occupational therapists in community mental health. Br J Occup Ther 2004; 67: 118-124.

90 Marquis R, Jackson R. Quality of life and quality of service relationships: experiences of people with disabilities. Disabil Soc 2000; 15: 411-425.

91 Bibyk B et al. Who's in charge here? The client's perspective on client-centred care. OT Now 1999; Sept/ Oct: $11-12$.

92 Corring DJ. The missing perspective on client-centred care. OT Now 1999; Jan-Feb: 8-10.

93 Rebeiro K. How qualitative research can inform and challenge occupational therapy practice. In: Hammell KW, Carpenter C (eds). Qualitative Research in Evidence-Based Rehabilitation. Churchill Livingstone: Edinburgh 2004, pp 89-102. 